\title{
Sports Rules As Common Pool Resources: A Better Way to Respond to Doping
}

\author{
Edward Castronova \\ Department of Telecommunications \\ Indiana University \\ Bloomington, IN 47405, U.S.A. \\ and \\ Gert G. Wagner \\ Department of Economics and Law \\ Berlin University of Technology \\ 10623 Berlin, Germany
}

In sports, as in all other fields of human life, there are written rules and then there are unwritten rules. An example of the former in soccer is the offside rule: a pass only is legal if at least two defenders are between a pass-receiver and the goal when the pass is made. An example of the latter is what might be called the "Injury Truce": if team A has an injured player and kicks out of bounds in order to stop play for medical treatment, after the time out team B kicks out of bounds itself to return possession to team A.

Players who violate either rule face negative consequences, the only difference being whether the consequence is enforced by the referee or not. For the offside rule, the referee grants a free kick for the other team. For the injury truce, violation leads to rough play on the field and stigma off the field within the crowd of spectators. Both consequences are negative and both cause the rule to be followed. Athletes are humans, and their personal incentives are not described entirely by the formal rules in a game. Informal rules matter.

Sports rules are also a response to the common property resource (CPR) problem posed by any game: The game is more fun (and economically more valuable to players and spectators alike) if it is played according to certain rules. Yet absent some kind of enforcement, breaking the rules is always in the interests of every single player. It easier to score by going offsides. It is also easier to score if an opponent is on the ground, injured. Yet a game where players crowd the goal and ruthlessly trample one another into the turf is less fun for all, and worth less money, than a game in which players must run to the goal and allow opponents time to recover from injury. The classic CPR regulation problem results: If it is in everyone's individual interest to violate a norm that is in the collective interest, how does one change individual incentives?

The two classic regulatory CPR approaches are centralized and decentralized. Written and unwritten rules are examples of each approach respectively. Some times centralized 
enforcement with written rules is the best way to respond to a CPR problem. At other times, the decentralized approach is best. Political scientists have established a deep body of knowledge about when to apply each of these different approaches. ${ }^{1}$

Written rules work well when behaviour is easy to observe and a central authority can easily impose appropriate sanctions. When behaviour is hard to observe and imposing sanctions is costly, decentralized mechanisms are much better.

We first wrote about this over a decade ago (Bird and Wagner 1997), when we noticed that golf has rules about things that are very difficult to detect (such as the degree angle of grooves on club heads), but these are effectively enforced by extremely powerful informal rules. In that paper, we noted that golfers will voluntarily disqualify themselves from tournaments when they break even obscure rules, even if no one else saw them break the rule. They do this to preserve their reputation among fellow golfers and competitors. Having a poor reputation in golf, it turns out, makes it really hard to succeed at the actual game. Other players will give you a hard time by disturbing you, which affects your nerves, which makes you slice into the trees.

This, it seems to us, golf rules are offering a route to better enforcement strategies in the area of doping. The doping problem is more like golf problems than the offside phenomena in soccer: Violations of doping rules are hard to detect and sanctions are hard to enforce. We note many reasons why improper use of substances will always be difficult to observe and sanction: New substances are coming out all the time, many substances are "natural" and won't show up in the bloodstream; some substances are perfectly appropriate at some times (like when an athlete is really sick) and not at others. CPR research indicates that because of its basic structure, this problem cannot be addressed by centralized regulation. The then- (and tragically still-) current method of publishing a list of banned substances and enforcing the list can never, ever work.

Under centralized doping control, it is the nature of the sport's ecology that athletes will take any substance they can to improve the chance of winning. If they have the chance to take substances which are not on the "doping list" they do not face any penalty risk. And if they take substances which are not possible or very difficult to detect they face no penalty risk or a marginal one only. Ten years age we therefore predicted that any sport in which athletes might benefit from dope, where enforcement was centralized, will naturally and always have many doped athletes. We were right. Since our paper, the problem of doping in sports has not changed. For example: in America's cherished traditional sport, baseball, an entire era of records is now open to question because so many players have been using steroids - despite an allegedly "tough" enforcement scheme. We said that it doesn't matter how "tough" an enforcement scheme is - if it is centralized, it will fail. And baseball's steroid policy has failed, as has centralized doping enforcement in virtually every other major sport. We predict: it is just a matter of time and the actual track and field stars will face problems with new kinds of detection instruments.

Centralized enforcement has failed for obvious reasons, and those same reasons (observation and sanction problems) predict that decentralized enforcement will work, as it does in golf. 
Decentralized enforcement of doping norms would be fairly simple to do. All that is required is that any one athlete can find out about the drug regimen of another athlete, and then impose stigma on that athlete if something is amiss. One could state a norm that anyone who uses substances - and all athletes do - must keep accurate records of what they used, and when. We called this system the "Drug Diary." Other athletes and the public (via journalists) should be given access to these records. Athletes who keep shady records will of course become suspect. Those who keep good records but are positively pickled will lose the respect of their colleagues. All that is needed then is some mechanism whereby the bad reputation and disrespect of other athletes is translated into poor performance on the field. However, the core of the new enforcement scheme would be a self enforcing mechanism amongst the athletes themselves. In golf, the disrespect of one golfer interferes with another through the mechanism of "gaming" - of pestering other golfers about possible rules violations, forcing them to check things, delaying their play, and generally trying to disrupt their concentration. Such methods might invite response, but even in that case the two golfers would end up spending their precious calm on a squabble and wind up with lower scores. Thus generally the gaming behaviour happens usually against only one bad apple - everyone gangs up on that one guy, wrecking his game while keeping everyone else's game intact.

The analog in doping would be that any one athlete could be subjected to tests and investigations at any time if another athlete requests it. Note that the use of drugs itself would not be a reason for a penalty; rather, the penalty applies for using a drug without declaring it. This changes incentives in powerful ways. Athletes who use new drugs, drugs not on any list, face no penalty risk today, but under this system they would face a penalty risk if they did not declare what they were using. Imagine a sprinter heading out to the track being stopped five times in a row for blood tests demanded by five separate competitors; her performance would be affected. As in golf, trivial testing would be discouraged by the norms; anyone who demanded too many tests or investigations would themselves become subject to the stigma of others.

On top of this system the common drug detection technologies could still be applied: an athlete who uses drugs not listed in his drug diary would be penalized by the sport organization. So - and this was the basic idea of our proposal - it would no longer be possibile to dope by means of new drugs (which are not listed yet) because any use of non-declared drugs would become very risky.

This approachhas not been implemented by any enforcement body, to our knowledge. We believe that is never was implemented because sport organizations realized that this approach would destroy the illusion of a drug-free "clean" sport. However, one sport, Weightlifting, has explicitly split into drug-free and drugged versions, a development we predicted might happen if Drug Diaries became common. ${ }^{2}$ We speculated that if everyone knew what everyone was taking, some fans and athletes might voluntarily split off and form a no-drug version of the sport, while others, those who crave maximum performance at any cost, would stay within a high-output, high-drug version. Perhaps the state of information in professional sport today is exactly this: Everyone knows that athletes are taking everything they can get. We all know

2 "USA Powerlifting: The Choice For Drug-Free Strength Sport." Emphasis in the original. Observed October 7, 2009 at http://www.usapowerlifting.com/. 
that all athletes are putting powerful substances into their bodies. With that knowledge now being common, perhaps things will begin to change.

Perhaps many people are now starting to wonder what sport might look like among "normal" people. Perhaps many athletes are tired of trading their health for medals. If so, then the development of drug-free Weightlifting might herald a wider change in professional sports. The central-control sports, where the idiocies of the enforcement system ensure that all athletes are doped to the four winds, might lose prominence as norm-enforcement sports emerge where athletes are relatively "clean." Such a development would certainly be predicted under the CPR model of sports rules, and this model, in the last decade at least, has been strongly validated by events in the area of performance enhancing drugs. 